See discussions, stats, and author profiles for this publication at: https://www.researchgate.net/publication/308456173

\title{
Loyalitas Nasabah Tabungan : Peran Nilai dan Kualitas Hubungan
}

Thesis · September 2016

DOI: 10.13140/RG.2.2.23475.02085

3 authors, including:

$$
\text { Herman Sjahruddin }
$$

Brawijaya University

56 PUBLICATIONS 31 CITATIONS

SEE PROFILE

Some of the authors of this publication are also working on these related projects:

Extreme Behaviour View project

Financial Banking View project
1 PUBLICATION 0 CITATIONS

SEE PROFILE 


\title{
Loyalitas Nasabah Tabungan : Peran Nilai dan Kualitas Hubungan
}

\section{Loyalitas Nasabah Tabungan : \\ Peran Nilai dan Kualitas Hubungan}

\author{
Hikmawati $^{1 *)}$, Herman Sjahruddin ${ }^{2)}$, Orfyanny S. Themba ${ }^{3)}$ \\ hikmimhe@gmail.com \\ ${ }^{1,2,3)}$ Sekolah Tinggi Ilmu Ekonomi Makassar (STIEM) Bongaya
}

\begin{abstract}
ABSTRAK
Studi ini bertujuan untuk menguji dan menganalisis pengaruh nilai pelanggan dan Kualitas hubungan terhadap loyalitas nasabah. 58 Nasabah PT Bank Mandiri (Persero), Tbk Area Makassar Kartini digunakan sebagai sampel. Hasil penelitian memberikan bukti bahwa nilai pelanggan berpengaruh positif dan signifikan terhadap loyalitas nasabah yang diakibatkan karena penggunaan transaksi perbankan memberikan rasa aman kepada nasabah dan bank ini selalu bersikap cepat dalam menanggapi keluhan nasabah. Kualitas hubungan berpengaruh positif dan signifikan terhadap loyalitas nasabah. Hal ini disebabkan karena nasabah merasa nyaman dan aman dengan dana yang di investasikan nasabah pada bank ini dan pihak perbankan memiliki responsif yang tinggi dalam menanggapi keluhan nasabah.
\end{abstract}

Kata Kunci: Nilai Pelanggan, Kualitas Hubungan, Loyalitas Nasabah

\section{PENDAHULUAN}

Bisnis perbankan merupakan bisnis kepercayaan. Bank harus mampu memberikan rasa aman pada nasabahnya menyangkut dana yang disimpan atau dikelola oleh bank tersebut. Dalam hal penghimpunan dana masyarakat yang merupakan salah satu sumber dana bank terbesar yang dalam hal ini adalah tabungan, deposito dan giro. Bank merupakan mitra marsyarakat dalam rangka memenuhi semua kebutuhan keuangan masyarakat. Semakin meningkatnya persaingan dalam bisnis perbankan menuntut setiap bank untuk selalu memperhatikan kebutuhan dan keinginan nasabah. Perbankan dituntut untuk mengoptimalkan kualitas pelayanan kepada nasabah sebaik-baiknya agar kepuasan nasabah tetap terjaga. Bank yang mampu memenuhi kepuasan yang diinginkan pelanggannya maka yang akan diperoleh adalah kesetiaan dan loyalitas dari para nasabahnya (Imasari dan Nursalin, 2011).

Loyalitas nasabah merupakan salah satu kunci kesuksesan perbankan, loyalitas memerlukan minat agar dapat diwujudkan secara nyata. Minat mengarahkan perhatian, rasa tertarik, keinginan, dan motif nasabah untuk merealisasikan loyalitas (Febriyan dan Sulistyowaty, 2014:51). Berdasarkan teorinya, loyalitas terbentuk dari kepuasan (teori diskonfirmasi harapan atau 


\section{Loyalitas Nasabah Tabungan : Peran Nilai dan Kualitas Hubungan}

expectancy - disconfirmation theory) yang menjelaskan bahwa nasabah akan loyal terhadap perbankan setelah produk atau jasa yang telah digunakan, hasilnya dapat dibandingkan dengan harapan (ekspektasi) nasabah, jika hasilnya sesuai dengan harapan nasabah berarti telah terjadi konfirmasi, sedangkan diskonfirmasi terjadi ketika ada perbedaan antara harapan dan hasil.

Loyalitas nasabah disebabkan oleh konfirmasi atau diskonfirmasi positif dari harapan (ekspektasi) dan ketidakpuasan disebabkan oleh diskonfirmasi negatif dari harapan pelanggan (Oliver, 1980; dalam Ramli dan Sjahruddin, 2015).

Loyalitas merupakan efek akhir dari suatu pembelian, yang diartikan sebagai suatu sikap dan niat untuk berperilaku dimasa depan, dan diekspresikan melalui hal-hal seperti; komitmen untuk membeli kepada perusahaan jika membutuhkan produk lainnya; komitmen untuk memberikan rekomendasi kepada orang lain: niat untuk menambah jumlah tabungan; niat atau keinginan untuk mencirikan hal-hal yang positif tentang perusahaan; dan kesediaan untuk membayar mahal (beban biaya). Loyalitas nasabah berawal dari pelayanan perusahaan yang memuasakan sehingga menghasilkan kepuasan pelanggan. Kepuasan pelanggan adalah membandingkan antara kinerja yang dirasakan dengan yang diharapakan (Kotler dan Keller, 2007).

Terdapat beberapa faktor yang mempengaruhi loyalitas nasabah, antara lain; kepuasan konsumen (costumer satisfaction), nilai pelanggan (costumer value), ikatan emosi (emotional bonding), kepercayaan (trust), kemudahan (choice reduction and habit), dan pengalaman perusahaan (history with company) (Palilati, 2007; Zikmund dalam Vanessa, 2007:72).

Berdasarkan faktor-faktor tersebut, maka penelitian ini difokuskan pada nilai pelanggan dan relationship quality, hal ini disebabkan karena pada umumnya nasabah melakukan aktifitas menabung dipengaruhi oleh dua hal pokok yaitu nilai pelanggan (costumer value) dan kualitas hubungan antara pihak bank dengan nasabah (relationship quality). Pemilihan kedua variabel tersebut dipilih disebabkan karena variabel nilai pelanggan (costumer value) dan hubungan antara pihak bank dengan nasabah (relationship quality) menjadi penyebab utama, nasabah dalam memilih produk tabungan (Palilati, 2007).

Hasil penelitian terdahulu membuktikan bahwa nilai pelanggan berpengaruh terhadap loyalitas nasabah, ditunjukkan pada penelitian Palilati (2007), bahwa terdapat hubungan langsung yang positif dan signifikan antara nilai nasabah dengan loyalitas nasabah. Perbedaan temuan dalam menjelaskan pengaruh nilai pelanggan terhadap loyalitas nasabah 


\section{Loyalitas Nasabah Tabungan : Peran Nilai dan Kualitas Hubungan}

ditunjukkan pada penelitian yang dilakukan Hidayat (2009), bahwa nilai produk berpengaruh negatif dan tidak signifikan terhadap loyalitas nasabah.

Pengaruh antara variabel lainnya yang dibangun dalam penelitian ini adalah relationship quality, bahwa relationship quality atau kualitas hubungan, dapat juga disebut sebagai kualitas kerelasian. Kualitas sebuah hubungan merupakan fungsi dari beberapa elemen atau faktor-faktor tertentu di antaranya: ko-operasi, kemampuan dan kinerja karyawan termasuk manajer, sumber daya fisik, kualitas, distribusi dan penentuan harga produk, pembagian informasi, pengalaman, harapan konsumen dan kepuasan (Zineldin et al., 1997; dalam Rahardian, 2011).

Kualitas Hubungan (relationship quality) berpengaruh positif dan signifikan terhadap loyalitas nasabah (Panjaitan, 2011). Perbedaan temuan dalam menganalisis pengaruh kualitas hubungan terhadap loyalitas nasabah ditunjukkan dalam penelitian Hidayat (2009) bahwa kualitas hubungan yang dicirikan melalui Kualitas layanan berpengaruh negatif dan tidak signifikan terhadap loyalitas nasabah. Berdasarkan kesenjangan temuan peneliti terdahulu dan fakta lapang ,maka penelitian ini dilakukan dengan judul Pengaruh Nilai Pelanggan, Relationship Quality Terhadap Loyalitas Nasabah Tabungan

\section{TINJAUAN PUSTAKA}

\section{A. Pengertian Bank}

Bank secara sederhana dapat diartikan sebagai lembaga keuangan yang kegiatan utamanya adalah menghimpun dana dari masyarakat baik secara langsung berupa tabungan, giro dan deposito maupun secara tidak langsung berupa kertas berharga; penyertaan dan sebagainya yang kemudian menyalurkan kembali dana tersebut ke masyarakat serta memberikan jasa bank lainnya. Pandangan lainnya menjlaskan bahwa bank didefinisikan sebagai lembaga keuangan yang kegiatan utamanya adalah menghimpun dana dari masyarakat dan menyalurkannya kembali dana tersebut ke masyarakat serta memberikan jasa bank lainnya (Kasmir, 2008:11).

\section{B. Konsep Nilai Pelanggan}

\section{Pengertian Nilai Pelanggan}

Nilai pelanggan adalah rasio antara keuntungan atau manfaat yang dirasakan dengan pengorbanan yang dikeluarkan (Monroe dalam Gaffar Vanessa, 2007:65). Dimana keuntungan yang dirasakan adalah kombinasi dari atribut fisik, atribut jasa dan teknik pendukung dalam pemanfaatan produk. Pengorbanan yang dikeluarkan adalah total biaya yang 


\section{Loyalitas Nasabah Tabungan : Peran Nilai dan Kualitas Hubungan}

dikeluarkan konsumen termasuk biaya pembelian dan biaya tambahan serta biaya diluar pembelian.

\section{Pengukuran Nilai Pelanggan}

Pengukuran nilai pelanggan, menurut Paliati (2007) ditunjukkan dengan indikator :

a. Fungsi transaksi, pemindahbukuan merupakan proses pelayanan yang dirasakan oleh nasabah dalam melakukan transaksi termasuk pemindah bukuan.

b. Hadiah adalah pemberian (kenang-kenangan, penghargaan, penghormatan) yang diberikan kepada nasabah untuk meningkatkan kedekatan social.

\section{Konsep Kualitas Hubungan}

\section{Pengertian Kualitas Hubungan}

Kualitas hubungan menurut Hennig Thurau dan Klee (2007) adalah tingkat kesesuaian dalam memenuhi kebutuhan pelanggan yang terkait dengan produk dan kualitas produk secara keseluruhan. Sebuah produk yang memenuhi kebutuhan pelanggan adalah produk yang memiliki kualitas yang tinggi. Chen, dkk., (2011:17) menyatakan bahwa kualitas kerelasian adalah pendekatan komprehensif untuk menciptakan, mempertahankan dan meningkatkan hubungan dengan konsumen. Pada kualitas kerelasian, penarikan pelanggan baru hanyalah langkah awal dari proses pemasaran (Pi dan Huang, 2011).

\section{Pengukuran Kualitas Hubungan}

Menurut Morgan dan Hunt (1994), Relationship quality dapat dijelaskan melalui dua indikator pengukuran, yaitu:

a. Kepercayaan (trust) merupakan kesediaan nasabah menerima resiko dari pihak perbankan berdasarkan keyakinan dan harapan bahwa pihak perbankan akan melakukan tindakan sesuai yang diharapkan nasabah.

b. Komitmen (Commitment) dianggap juga sebagai masalah utama dalam relationship marketing.

\section{Konsep Loyalitas Nasabah}

\section{Pengertian Loyalitas Nasabah}

pada dasarnya setiap perusahaan yang melakukan program pelayanan prima maka akan menciptakan kepuasan pelanggan. Pelanggan yang memperoleh kepuasan dalam pelayanan merupakan modal dasar bagi perusahaan dalam membentuk loyalitas pelanggan. 


\section{Loyalitas Nasabah Tabungan : Peran Nilai dan Kualitas Hubungan}

Loyalitas pelanggan adalah komitmen pelanggan terhadap suatu merek, toko, dan pemasok, berdasarkan sikap yang sangat positif dan tercermin dalam pembelian ulang yang positif (Tjiptono, dan Chandra 2007). Sedangkan menurut Gaffar Venessa (2007) bahwa loyalitas pelanggan merupakan komitmen pelanggan untuk bertahan secara mendalam untuk berlangganan kembali atau melakukan pembelian ulang produk/jasa terpilih secara konsisten dimasa yang akan datang, meskipun pengaruh situasi dan usaha-usaha pemasaran mempunyai potensi untuk menyebabkan perubahan perilaku.

\section{Pengkuran Loyalitas Nasabah}

Wijayanti (2010) menyebutkan beberapa indikator loyalitas, yaitu:

a. Loyalitas pelanggan dan kepuasannya adalah berkaitan,walaupun keterkaitannya adalah tidak selalu beriringan. Kepuasan merupakan tingkat kepuasan seseorang setelah membandingkannya dengan kinerja atau hasil yang dirasakan dengan harapan mereka.

b. Kualitas jasa merupakan tingkat keunggulan yang diharapkan dalam pengendalian atas keunggulan tersebut untuk memenuhi kebutuhan pelanggan.

c. Citra diartikan sebagai kesan seseorang atau individu tentang sesuatu yang muncul sebagai hasil dari pengetahuan dan pengalamannya menggunakan produk atau jasa bank.

\section{METODE PENELITIAN}

Model pengukuran nilai pelanggan mengembangkan pengukuran yang digunakan Mediana (2010), yang dicerminkan melalui fungsi transaksi dan hadiah. Pada pengukuran kualitas hubungan digunakan pengukuran, yang meliputi; keprcayaan dan komitmen (Morgan dan Hunt, 1994). Kemudian untuk loyalitas nasabah diukur dengan kepuasan pelanggan, kualitas jasa, dan citra (Wijayanti, 2010).

Pelaksanaan penelitian ini dilakukan pada PT. Bank Mandiri (Persero) Tbk, Area Makassar Kartini. Sedangkan waktu yang digunaan dalam melakukan penelitian ini kurang lebih selama dua bulan. 58 nasabah bank digunakan sebagai Populasi.

Teknik pengambilan sampel dilakukan dengan menggunakan sampel acak sederhana. Pengukuran variabel dalam penelitian ini yang diukur menggunakan Skala Ordinal dengan menggunakan Skala Likert point 1 sampai dengan point 5 untuk jawaban sangat setuju (SS). 


\section{Loyalitas Nasabah Tabungan : Peran Nilai dan Kualitas Hubungan}

IV. HASIL PENELITIAN

A. Distribusi Responden Berdasarkan Jenis Kelamin

Tabel 1

Karakteristik responden berdasarkan jenis kelamin

\begin{tabular}{llrr}
\hline & & Frequency & \multicolumn{1}{c}{ Percent } \\
\hline Valid & Perempuan & 35 & 60.3 \\
& laki-laki & 23 & 39.7 \\
& Total & 58 & 100.0 \\
\hline
\end{tabular}

Sumber : Data diolah (2016)

Responden didominasi oleh perempuan kondisi tersebut menjelaskan bahwa perempuan lebih sering menggunakan jasa layanan transaksi dibandingkan laki-laki, karena pada saat dilakukannya pedistribusian kuesioner tingkat partisipasi perempuan lebih tinggi dibandingkan laki-laki.

\section{B. Distribusi Responden Berdasarkan Usia}

\section{Tabel 2}

Karakteristik responden berdasarkan Usia

\begin{tabular}{llcr}
\hline & Freq. & Percent \\
\hline Valid & $\leq 20$ Tahun & 10 & 17.2 \\
& $\leq 30$ Tahun & 42 & 72.4 \\
& $\leq 40$ Tahun & 6 & 10.3 \\
& Total & 58 & 100.0 \\
& & & \\
\hline
\end{tabular}

Sumber : Data diolah (2016)

Berdasarkan kelompok usia, responden dicirikan melalui interval usia : $\leq 30$ Tahun yaitu sebanyak 42 orang atau sebesar $72,40 \%$. Hal ini menjelaskan bahwa nasabah bank berada dalam kelompok usia relative muda.

\section{Distribusi Responden Berdasarkan Status Pernikahan}

Berdasarkan status pernikahan ditemukan bahwa responden yang belum menikah lebih banyak dibandingkan dengan status lainnya, yakni sebanyak 41 orang atau sebesar $70,7 \%$. Kondisi tersebut menjelaskan bahwa 


\section{Loyalitas Nasabah Tabungan : Peran Nilai dan Kualitas Hubungan}

intensitas penggunaan jasa perbankan cenderung digunakan oleh nasabah yang belum menikah.

Tabel 3

Karakteristik responden berdasarkan Status Pernikahan

\begin{tabular}{llrr}
\hline & Frequency & \multicolumn{2}{c}{ Percent } \\
\hline Valid & Nikah & 15 & 25.9 \\
& Belum Nikah & 41 & 70.7 \\
& Janda/Duda & 2 & 3.4 \\
& Total & 58 & 100.0 \\
\hline
\end{tabular}

Sumber : Data diolah (2016)

\section{Distribusi Responden Berdasarkan Tingkat Pendidikan}

Kategori Responden berdasarkan tingkat pendidikan di dominasi dengan jenjang pendidikan terakhir SMU, yaitu sebanyak 25 orang atau sebesar $43,10 \%$. Data tersebut menjelaskan bahwa intensitas penggunaan transaksi atau jasa layanan perbankan pada saat dilakukannya penyebaran kuesioner ini di dominasi oleh nasabah dengan jenjang pendidikan terakhir SMU.

Tabel 4

Karakteristik responden berdasarkan Tingkat Pendidikan

\begin{tabular}{llrr}
\hline & Frequency & \multicolumn{2}{c}{ Percent } \\
\hline Valid & SMU & 25 & 43.1 \\
& Diploma & 6 & 10.3 \\
& Strata Satu & 24 & 41.4 \\
& Strata Dua & 3 & 5.2 \\
& Total & 58 & 100.0 \\
\hline
\end{tabular}

Sumber : Data diolah (2016)

\section{E. Distribusi Responden Berdasarkan Pekerjaan}

Dominasi nasabah ditunjukkan melalui nasabah dengan pekerjaan sebagai pegawai swasta. Kondisi tersebut menjelaskan bahwa intensitas penggunaan jasa layanan perbankan pada saat dilakukannya pendistribusian kuesioner ini lebih sering dimanfaatkan oleh pegawai swasta. Hal ini disebabkan aktifitas pegawai swasta yang lebih intens dalam dunia bisnis 


\section{Loyalitas Nasabah Tabungan : Peran Nilai dan Kualitas Hubungan}

yang kemudian menjadi alasan bagi mereka menggunakan jasa layanan perbankan

Tabel 5

Karakteristik Responden berdasarkan Pekerjaan

\begin{tabular}{llrr}
\hline & Frequency & \multicolumn{2}{c}{ Percent } \\
\hline Valid & PNS/TNI/ POLRI & 2 & 3.4 \\
& Pegawai Swasta & 35 & 60.3 \\
& Lain-lain & 21 & 36.2 \\
& Total & 58 & 100.0 \\
\hline
\end{tabular}

Sumber : Data diolah (2016)

\section{F. Distribusi Responden Berdasarkan Lamanya menjadi Nasabah}

Tabel berikut menunjukkan bahwa lamanya seseorang menjadi nasabah yaitu pada interval waktu kurang dari atau sama dengan 15 tahun, dengan demikian dapat disimpulkan bahwa pada umumnya nasabah memiliki tingkat loyalitas yang tinggi.

Tabel 6

Karakteristik responden berdasarkan lamanya menjadi nasabah

\begin{tabular}{llrr}
\hline & & Freq. & Percent \\
\hline Valid & 11 & 22.0 \\
& $\leq 10$ Tahun & 17 & 34.0 \\
& $\leq 15$ Tahun & 22 & 44.0 \\
& Total & 50 & 100.0 \\
& & & \\
\hline
\end{tabular}

Sumber : Data diolah (2016)

\section{G. Uji Kesusaian Model}

Tabel 7

Model fit dan quality indices

\begin{tabular}{ll}
\hline APC & $0.478, \mathrm{P}<0.001$ \\
\hline ARS & $0.798, \mathrm{P}<0.001$ \\
AFVIF & $2.055<5$ \\
\hline
\end{tabular}

Sumber : Data diolah (2016) 


\section{Loyalitas Nasabah Tabungan : Peran Nilai dan Kualitas Hubungan}

P-value untuk Average path coefficient (APC) dan ARS dan nilai Average R-squared (ARS) harus $<0,05$ atau berarti signifikan. Selain itu Average full collinearity VIF (AFVIF) sebagai indikator multikolinearitas harus $<5$. Hasil penelitian menunjukkan bahwa kriteria goodness of fit model telah terpenuhi (Kock, 2011).

\section{H. Pengukuran Model}

Measurement model atau outer model yaitu validitas dan reliabilitas konstruk. Output ini digunakan peneliti untuk melaporkan hasil pengujian validitas konvergen dari instrumen pengukuran (kuesioner). Hasil pengujian pada model ini sudah terpenuhi karena telah memenuhi syarat, validitas konvergen sebesar > 0,70 dan signifikan (p-value < 0,05). (Hair et al., 2013).

Tabel 8

Combined Loading dan cross-loadings

\begin{tabular}{llllll}
\hline & NL_Nas & K_Hub $_{-}$ & Lyl_nas & SE & P value \\
\hline $\mathrm{X}_{11}$ & $(0.906)$ & 0.215 & 0.006 & 0.095 & $<0.001$ \\
$\mathrm{X}_{12}$ & $(0.906)$ & -0.215 & -0.006 & 0.095 & $<0.001$ \\
$\mathrm{X}_{21}$ & 0.086 & $(0.809)$ & 0.212 & 0.098 & $<0.001$ \\
$\mathrm{X}_{22}$ & -0.086 & $(0.809)$ & -0.212 & 0.098 & $<0.001$ \\
$\mathrm{Y}_{11}$ & -0.023 & 0.261 & $(0.866)$ & 0.096 & $<0.001$ \\
$\mathrm{Y}_{12}$ & 0.546 & -0.160 & $(0.840)$ & 0.097 & $<0.001$ \\
$\mathrm{Y}_{13}$ & -0.506 & -0.105 & $(0.867)$ & 0.096 & $<0.001$ \\
\hline
\end{tabular}

Sumber : Data diolah (2016)

\section{Uji Validitas Deskriminan}

Uji validitas diskriminan dibuktikan melalui hasil output latent variable correlations. Output ini melaporkan koefisien korelasi antar variabel laten. Kriteria yang digunakan adalah akar kuadrat (square roots) average variance extracted (AVE) yaitu kolom diagonal yang diberi tanda kurung harus lebih tinggi dari korelasi antar variabel laten pada kolom yang sama (di atas atau di bawahnya) (Sholihin, M \& Dwi R, 2013).

Tabel 9

Correlations among l.vs. with sq. rts. of AVEs

\begin{tabular}{llll}
\hline & NL_Pel & K_Hub & Lyl_nas \\
\hline NL_Pel & $(0.906)$ & 0.697 & 0.852 \\
K_Hub & 0.697 & $(0.809)$ & 0.771 \\
Lyl_nas & 0.852 & 0.771 & $(0.858)$ \\
\hline
\end{tabular}

Sumber : Data diolah (2016) 


\section{Loyalitas Nasabah Tabungan : Peran Nilai dan Kualitas Hubungan}

Tabel tersebut menunjukkan bahwa validitas diskriminan telah terpenuhi, yaitu dapat dilihat dari akar AVE pada kolom diagonal lebih besar daripada korelasi antar konstruk pada kolom yang sama.

\section{J. Uji Realibilitas Konstruk}

Koefisien determinasi menggunakan $R$-squared yang menunjukan berapa presentase variansi konstruk endogen/kriterion dapat dijelaskan oleh konstruk yang dihipotesiskan mempengaruhinya. Semakin tinggi R-squared menunjukkan model yang baik. Dari hasil output Latent Variable Coeffisient menunjukkan $R$-squared loyalitas nsabah 0.798 artinya variansi loyalitas nasabah dapat dijelaskan sebesar $79,80 \%$ oleh variansi nilai pelanggan dan kualitas hubungan. Nilai composite relibiality dan cronbach alpha telah memenuhi syarat reliabilitas yaitu $>0,70$. Output di atas juga menunjukkan bahwa Average Variance Extracted (AVE) > 0,50 yang artinya telah memenuhi syarat validitas konvergen (Sholihin, A \& Dwi R, 2013).

Tabel 10 Reliabilitas konstruk

\begin{tabular}{lccc}
\hline & NL_Pel & K_Hub & Lyl_Nas \\
\hline R-squared & & & 0.798 \\
Adj. R-squared & & & 0.791 \\
Composite reliab. & 0.902 & 0.791 & 0.893 \\
Cronbach's alpha & 0.782 & 0.472 & 0.820 \\
Avg. Var. Extrac & 0.821 & 0.655 & 0.736 \\
Full collin VIF & 3.708 & 2.499 & 4.690 \\
Q-squared & & & 0.798 \\
Min & -3.162 & -3.387 & -2.649 \\
Max & 1.915 & 2.038 & 2.063 \\
Median & -0.083 & 0.114 & 0.001 \\
Modes & -0.386 & -0.958 & 0.644 \\
Skewness & -0.738 & -0.347 & -0.078 \\
Exc. kurtosis & 1.324 & 0.860 & 0.084 \\
\hline Sumber Data diolah $(2016)$ & & &
\end{tabular}

Sumber : Data diolah (2016)

Full collinearity VIF merupakan hasil pengujian kolinearitas penuh yang meliputi multikolinearitas vertikal dan lateral. Kolinearitas lateral adalah kolinearitas antara variabel laten prediktor dengan kriterion. Kolinearitas lateral sering diabaikan padahal dapat menyebabkan hasil penelitian menjadi bias. Full collinearity VIF dalam penelitian ini nilainya lebih rendah dari 3,3 hal ini menunjukkan bahwa model bebas dari masalah kolinearitas vertikal, lateral, dan commond method bias. (Kock, 2013). Qsquared merupakan ukuran non parametrik yang diperoleh melalui algoritma blindfolding dan digunakan untuk penelitian validitas prediktif 


\section{Loyalitas Nasabah Tabungan : Peran Nilai dan Kualitas Hubungan}

atau relevansi dari sekumpulan variabel laten prediktor pada variabel kriterion. Output menunjukkan Q-squared lebih besar dari nol yaitu 0.798 artinya estimasi model menunjukan validitas prediktif yang baik. Secara keseluruhan, hasil measurement model (outer model) konstruk reflektif telah memenuhi syarat.

\section{K. Model dan pengujian hipotesis}

Tabel 11 Koefisien Jalur

\begin{tabular}{lcccc}
\hline & \multicolumn{2}{c}{ NL_Pel } & K_ Hub & Lyl_Nas \\
\hline & P values & Path coefficient & P values & Path coefficient \\
NL_Pel & & & & \\
K_Hub & & & & \\
Lyl_Nas & $<0.001$ & 0.638 & 0.004 & 0.318 \\
\hline
\end{tabular}

Sumber : Data diolah (2016)

\section{PEMBAHASAN}

1. Pengaruh Nilai Pelanggan Terhadap Loyalitas Nasabah

Hasil penelitian ini menyatakan bahwa nilai pelanggan berpengaruh signifikan secara parsial terhadap loyalitas nasabah. Berdasarkan hasil pvalues, menunjukkan bahwa path koefisien bahwa nilai koefien jalur pengaruh nilai pelanggan loyalitas nasabah sebesar $<0.001$, koefisien bertanda positif mengandung arti bahwa jika nilai pelanggan meningkat maka loyalitas nasabah akan meningkat (searah). Hal ini dapat dibuktikan dengan $\mathrm{p}=$ value sebesar $<0.001$, bahwa pengaruh nilai pelanggan berpengaruh signifikan terhadap loyalitas nasabah. Sehingga dapat dijelaskan bahwa tingginya loyalitas nasabah memberikan pengaruh yang nyata terhadap peningkatan loyalitas nasabah, kondisi ini disebabkan karena karena penggunaan transaksi perbankan memberikan rasa aman kepada nasabah dan pihak bank selalu bersikap cepat dalam menanggapi keluhan nasabah. Hal ini menunjukkan bahwa nilai pelanggan mampu meningkatkan loyalitas nasabah. Ini berarti bahwa nilai pelanggan yang dibentuk oleh fungsi transaksi dan hadiah mampu meningkatkan loyalitas nasabah.

Hasil penelitian mendukung penelitian Palilati (2013) yang menunjukkan bahwa nilai pelanggan berpengaruh positif dan signifikan terhadap loyalitas nasabah. Hal ini menunjukkan bahwa nilai nasabah mampu meningkatkan loyalitas nasabah secara langsung. Hasil tidak berbeda dengan temuan penelitian Hidayat (2009) yang menyatakan bahwa nilai produk berpengaruh negatif dan tidak signifikan terhadap loyalitas nasabah. 


\section{Loyalitas Nasabah Tabungan : Peran Nilai dan Kualitas Hubungan}

2. Pengaruh kualitas hubungan Terhadap Loyalitas Nasabah

Kualitas hubungan berpengaruh signifikan terhadap loyalitas nasabah. Nilai p-values, menunjukkan bahwa nilai koefien jalur pengaruh kualitas hubungan terhadap loyalitas nasabah sebesar 0.318 , koefisien bertanda positif mengandung arti bahwa jika kualitas hubungan meningkat maka loyalitas nasabah akan meningkat juga (searah).

Hal ini dapat dibuktikan dengan $\mathrm{p}=$ value sebesar 0.004, bahwa pengaruh kualitas hubungan terhadap loyalitas nasabah signifikan terhadap loyalitas nasabah. Sehingga dapat dijelaskan bahwa tingginya kualitas hubungan memberikan pengaruh yang nyata terhadap peningkatan loyalitas nasabah.

Signifikannya pengaruh kualitas hubungan terhadap loyalitas nasabah disebabkan karena nasabah merasa nyaman dan aman dengan dana yang nasabah investasikan pada ban ini dan bank ini selalu bersikap cepat dalam menanggapi keluhan nasabah. Hal ini Ini berarti bahwa meningkatnya kualitas hubungan yang dibentuk oleh kepercayaan dan komitmen mampu meningkatkan loyalitas nasabah.

Hasil penelitian sejalan dengan temuan Panjaitan (2011) yang menunjukkan bahwa kualitas hubungan berpengaruh positif dan signifikan terhadap loyalitas nasabah. Hal ini menunjukkan bahwa kualitas hubungan mampu meningkatkan loyalitas nasabah secara langsung. Hasil tidak sejalan dengan penelitian Hidayat (2009) yang menyatakan bahwa kualitas hubungan berpengaruh negatif dan tidak signifikan terhadap loyalitas nasabah.

\section{KESIMPULAN}

\section{A. Kesimpulan}

1. Nilai Pelanggan Berpengaruh positif dan Signifikan Terhadap Loyalitas Nasabah. Koefisien jalur bertanda positif dan signifikan disebabkan karena penggunaan transaksi perbankan memberikan rasa aman kepada nasabah dan bank ini selalu bersikap cepat dalam menanggapi keluhan nasabah. Hal ini menunjukkan bahwa nilai nasabah mampu meningkatkan loyalitas nasabah.

2. Kualitas Hubungan Berpengaruh Positif dan Signifikan Terhadap Loyalitas Nasabah. Koefisien jalur bertanda positif dan signifikan disebabkan Koefisien karena nasabah merasa nyaman dan aman dengan dana yang nasabah investasikan pada bank ini dan bank ini selalu bersikap cepat dalam menanggapi keluhan nasabah. Hal ini 


\section{Loyalitas Nasabah Tabungan : Peran Nilai dan Kualitas Hubungan}

menunjukkan bahwa kualitas hubungan mampu meningkatkan loyalitas nasabah.

\section{B. SARAN}

1. Disarankan kepada bank untuk meningkatkan layanan transaksi yang dimiliki perbankan (pemindah bukuan, transfer, pengambilan,penyetoran) agar nasabah lebih merasa puas atas segala layanan transaksi yang dimiliki bank.

2. Peningkatan loyalitas nasabah dilakukan dengan memberikan perhatian terhadap kepercayaan nasabah agar untuk meningkatkan loyalitas nasabah bank harus memberikan rasa nyaman dan aman dengan dana yang nasabah investasikan pada bank.

3. Penelitian lebih lanjut diharapkan dapat dilakukan pada objek dan subjek yang berbeda dengan menambah variabel lain yang dipandang mampu menjelaskan loyalitas nasabah.

\section{DAFTAR PUSTAKA}

Bahri, Dinda. M. M., (2010). Analisis Pengaruh Nilai Pelanggan, Kualitas Pelayanan Dan Kedekatan Emosional Terhadap Loyalitas Nasabah (Studi Kasus Pada Bank BRI Cabang Pattimura) (Doctoral dissertation, Universitas Diponegoro).

Chen, S. C., Chiu, K. K. S., Huei-Huang, C., \& Liao, Y. C. (2011). A pilot study for understanding the relationships of information system quality, relationship quality and loyalty. Australian Journal of Business and Management Research, 1(5), 17.

Febriyan, H., \& Sulistyowati, L. (2014). pengaruh customer relationship management (crm) terhadap customer trust dan customer loyalty pada bank bri cabang pekanbaru imam munandar. Jurnal Tepak Manajemen Bisnis, 6(3), 51-60.

Gaffar F., Vanessa. 2007. Custumer Relationship Management dan Marketing Public Relation Hotel. Bandung: Alfabeta

Hair, J. F., Ringle, C. M., \& Sarstedt, M. (2013). Editorial-partial least squares structural equation modeling: Rigorous applications, better results and higher acceptance. Long Range Planning, 46(1-2), 1-12.

Hennig-Thurau, T., \& Klee, A. (1997). The impact of customer satisfaction and relationship quality on customer retention: A critical reassessment and model development. Psychology \& marketing, 14(8), 737-764.

Hidayat, R. (2009). Pengaruh kualitas layanan, kualitas produk dan nilai nasabah terhadap kepuasan dan loyalitas nasabah Bank Mandiri. Jurnal Manajemen dan Kewirausahaan (Journal of Management and Entrepreneurship), 11(1), pp-59. 


\section{Loyalitas Nasabah Tabungan : Peran Nilai dan Kualitas Hubungan}

Imasari, K., \& Nursalin, K. K. (2011). Pengaruh Customer Relationship Management terhadap Loyalitas Pelanggan pada PT BCA Tbk. Fokus Ekonomi, 10(3).

Kasmir. (2008). Bank dan Lembaga Keuangan Lainnya. Edisi Revisi 2008. Jakarta: PT. Rajagrafindo Persada

Kock, N. (2011). Using WarpPLS in e-collaboration studies: Descriptive statistics, settings, and key analysis results. International Journal of eCollaboration, 7(2), 1-17.

Kock, N. (2013). Using WarpPLS in E-Collaboration Studies: Descriptive Statistics, Settings. Interdisciplinary Applications of Electronic Collaboration Approaches and Technologies, 62

Kotler, Philip dan Kevin Lane Keller., (2007), Manajemen Pemasaran, Edisi Kedua Belas, Jilid 2, dialihbahasakan oleh Benjamin Molan, Jakarta: PT Indeks

Morgan, R.M. dan Hunt, S.D. (1994). The Commitment-Trust Theory of Relationship Marketing. Journal of Marketing, 58, (July), 20-38

Palilati, A. (2007). Pengaruh Nilai Pelanggan Kepuasan Terhadap Loyalitas Nasabah Tabungan Perbankan Di Sulawesi Selatan. Jurnal Manajemen dan Kewirausahaan (Journal of Management and Entrepreneurship), 9(1), pp-73.

Panjaitan, S. D. P. (2011). Pengaruh Kualitas Hubungan (Relationship Quality) Terhadap Loyalitas Pelanggan Doorsmeer Pada Cv. Balian Guru Medan.

Pi, W. P., \& Huang, H. H. (2011). Effects of promotion on relationship quality and customer loyalty in the airline industry: The relationship marketing approach. African Journal of Business Management, 5(11), 4403.

Rahardian, R. (2011). Pengaruh Trust dan Commitment Terhadap Relationship Quality Studi pada Perusahaan Pasangan Usaha PT. XYZ (Sebuah Lembaga Keuangan Non Bank). Jurnal Manajemen Teori dan Terapan| Journal of Theory and Applied Management, 4(3).

Ramli, A. H., \& Sjahruddin, H. (2015). Building Patient Loyalty in Healthcare Services. International Review of Management and Business Research, 4(2), 391.

Sholihin, M \& Dwi R. (2013). Analisis SEM-PLS dengan WarpPLS 3.0. Andi. Yogyakarta

Tjiptono, Fandy., dan Gregorius Chandra. (2007). Service, Quality, dan Satisfaction. Edisi 2.Andi Yogyakarta.

Wijayanti, A. W. (2010). Pengaruh Pelayanan dan Kepercayaan Anggota terhadap Kepuasan Anggota dan Loyalitas Anggota Koperasi Unit Desa (KUD) Mekar Ungaran (Doctoral dissertation, Universitas Negeri Semarang). 